\title{
COPD care delivery pathways in five European Union countries: mapping and health care professionals' perceptions
}

This article was published in the following Dove Press journal:

International Journal of COPD

14 November 2016

Number of times this article has been viewed

\author{
Reem Kayyali,' Bassel \\ Odeh,' Inéz Frerichs, ${ }^{2}$ Nikki \\ Davies, ${ }^{3}$ Eleni Perantoni, ${ }^{4}$ \\ Shona D'arcy, ${ }^{5}$ Anouk W \\ Vaes, ${ }^{6}$ John Chang, ${ }^{3}$ Martijn \\ A Spruit, ${ }^{6}$ Brenda Deering, ${ }^{7}$ \\ Nada Philip,' Roshan Siva, ${ }^{3}$ \\ Evangelos Kaimakamis, ${ }^{8}$ \\ loanna Chouvarda, ${ }^{8}$ Barbara \\ Pierscionek,' Norbert Weiler, ${ }^{2}$ \\ Emiel FM Wouters, ${ }^{6}$ Andreas \\ Raptopoulos, ${ }^{9}$ Shereen \\ Nabhani-Gebara' \\ 'Faculty of Science, Engineering and \\ Computing, Kingston University, \\ Kingston-Upon-Thames, UK; ${ }^{2}$ Department \\ of Anaesthesiology and Intensive Care \\ Medicine, University Medical Centre \\ Schleswig-Holstein, Kiel, Germany; ${ }^{3}$ Chest \\ Clinic and Research and Development, \\ Croydon University Hospital, Croydon,

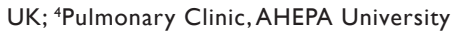 \\ Hospital, Thessaloniki, Greece; ${ }^{5}$ Department \\ of Medicine, Royal College of Surgeons \\ in Ireland, Dublin, Ireland; ' ${ }^{\circ}$ esearch and \\ Education, CIRO - Centre of Expertise \\ for Chronic Organ Failure, Horn, \\ the Netherlands; ${ }^{7}$ COPD Outreach, \\ Beaumont Hospital, Dublin, Ireland; \\ ${ }^{8}$ Medical School, Aristotle University, \\ Thessaloniki, ' $R$ esearch and Development, \\ Exodus Information Technology SA, \\ Athens, Greece
}

Background: COPD is among the leading causes of chronic morbidity and mortality in the European Union with an estimated annual economic burden of $€ 25.1$ billion. Various care pathways for COPD exist across Europe leading to different responses to similar problems. Determining these differences and the similarities may improve health and the functioning of health services. Objective: The aim of this study was to compare COPD patients' care pathway in five European Union countries including England, Ireland, the Netherlands, Greece, and Germany and to explore health care professionals' (HCPs) perceptions about the current pathways.

Methods: HCPs were interviewed in two stages using a qualitative, semistructured email interview and a face-to-face semistructured interview.

Results: Lack of communication among different health care providers managing COPD and comorbidities was a common feature of the studied care pathways. General practitioners/family doctors are responsible for liaising between different teams/services, except in Greece where this is done through pulmonologists. Ireland and the UK are the only countries with services for patients at home to shorten unnecessary hospital stay. HCPs emphasized lack of communication, limited resources, and poor patient engagement as issues in the current pathways. Furthermore, no specified role exists for pharmacists and informal carers.

Conclusion: Service and professional integration between care settings using a unified system targeting COPD and comorbidities is a priority. Better communication between health care providers, establishing a clear role for informal carers, and enhancing patients' engagement could optimize current care pathways resulting in a better integrated system.

Keywords: COPD, comorbidities, care delivery pathway, comparative analysis

\section{Introduction}

COPD is a common preventable and treatable pulmonary disease with symptoms of dyspnea, cough, and sputum production. ${ }^{1}$ COPD is among the leading causes of chronic morbidity and mortality in the European Union (EU) with 300,000 people with the condition dying each year. ${ }^{2}$ The prevalence of COPD has been increasing with different ratios nationally and even regionally. ${ }^{3,4}$ Table 1 summarizes COPD statistics in Germany, Greece, Ireland, the Netherlands, and the UK. ${ }^{5-8}$

The estimated annual economic burden of COPD in Europe, in terms of direct (health care) and indirect (lost production) costs, is $€ 25.1$ billion. ${ }^{4}$ In addition, acute exacerbations increase health care use, accelerate decline in lung function, and reduce patients' quality of life (QoL). ${ }^{1}$

Chronic diseases often develop together, and comorbidities markedly affect health outcomes in COPD. ${ }^{9}$ In fact, patients with COPD mainly die of nonrespiratory
Correspondence: Reem Kayyali

Faculty of Science, Engineering and Computing, Kingston University, Penrhyn Road, Kingston upon Thames KTI 2EE, United Kingdom Tel +442084l7256I

Email r.kayyali@kingston.ac.uk
International Journal of COPD 2016:II 283I-2838

(c) (7) ( 2016 Kayyali et al. This work is published and licensed by Dove Medical Press Limited. The full terms of this license are available at https://www.dovepress.com/terms.php (c) ${ }_{\mathrm{BY}} \mathrm{NC}$ and incorporate the Creative Commons Attribution - Non Commercial (unported, v3.0) License (http://creativecommons.org/licenses/by-nc/3.0/). By accessing the work you hereby accept the Terms. Non-commercial uses of the work are permitted without any further permission from Dove Medical Press Limited, provided the work is properly attributed. For permission

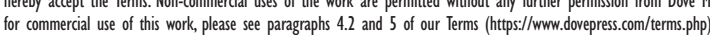


Table I COPD statistics in five European Union countries

\begin{tabular}{lllll}
\hline Country & $\begin{array}{l}\text { Total } \\
\text { expenditures } \\
\text { (US\$/capita) }\end{array}$ & $\begin{array}{l}\text { COPD } \\
\text { prevalence (\%) }\end{array}$ & $\begin{array}{l}\text { Hospital } \\
\text { admission } \\
\text { per 100,000 }\end{array}$ & $\begin{array}{l}\text { COPD } \\
\text { deaths } \\
\text { per 100,000 }\end{array}$ \\
\hline Germany & 3,764 & $13.2^{7}$ & 261.7 & 17.55 \\
Greece & 2,190 & - & - & 11.61 \\
Ireland & 3,026 & $9.8^{8}$ & 263.5 & 27.87 \\
the Netherlands & 4,160 & $13.2^{4}$ & 134.2 & 22.62 \\
UK & 2,899 & $12.4^{4}$ & 155.58 & 25.89 \\
\hline
\end{tabular}

Notes: “-”, no data. ${ }^{a}$ Data from OECD. Health expenditure and financing. OECD statistics-health. 20I5. Available from: http://stats.oecd.org/lndex.aspx?DataSetCode=SHA. ${ }^{5}$

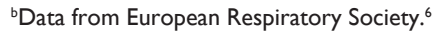

diseases ${ }^{10}$ such as cardiovascular diseases $(\sim 25 \%)$, cancers (mainly lung cancer, 20\%-33\%), and other causes (30\%). COPD is a frequent concomitant disease in patients with heart failure, and chronic heart failure is seen in $\geq 20 \%$ of primary care patients with stable COPD. ${ }^{9}$ Diabetes mellitus also affects $1.6 \%-16 \%$ of people with COPD, with prevalence increasing as lung function deteriorates. This prevalence has been found to be higher than in non-COPD patients. ${ }^{10,11}$ In addition, several studies have demonstrated that anxiety and depression are prevalent in COPD patients and lead to poorer disease-related outcomes and more frequent acute exacerbations and hospitalizations. ${ }^{12,13}$

The complex nature of COPD and its comorbidities requires integrated coordinated approaches, including a multidisciplinary team and explicit involvement of patients. ${ }^{14,15}$ Several studies have shown that integrated COPD care can reduce hospital admission and readmission rates, length of hospital stay, emergency department visits, mortality, disease costs, and overall fragmented care. ${ }^{16-23}$ Moreover, integrated care can reduce COPD patients' anxiety and depression and improve their health-related QoL and satisfaction. 19,20,22 This could potentially be attributed to the fact that integrated care improves disease knowledge, selfmanagement, early detection and treatment of exacerbations, and treatment adherence. ${ }^{19,22-24}$

Countries in Europe are implementing a range of approaches to better manage chronic diseases, meet the needs of patients, and facilitate sharing of experiences, thus enabling cross-country learning. ${ }^{14,15}$ However, countries often have different care pathways for long-term conditions and thus respond in different ways to similar problems. ${ }^{25}$ Even though these health systems differ widely in care settings, professional roles, and coordination mechanisms, there is an opportunity for these systems to learn from each other. ${ }^{14}$ Determining similarities and differences, using comparative research, can improve health and the functioning of health services. ${ }^{26}$ In addition, using health care professionals' (HCPs) experience and perception could be beneficial as it increases the chances of adapting any solutions or interventions during implementation.

In this study, the care pathway for patients with COPD was compared across five countries: England, Ireland, the Netherlands, Greece, and Germany. The purpose was to explore the similarities and differences in the care pathways and the services provided to patients, in addition to exploring HCPs' perceptions about the current pathways.

\section{Methods}

This was a two-phase study conducted as a part of the WELCOME project (http://www.welcome-project.eu). ${ }^{27}$ It mapped the current COPD patients' care pathways as a first stage and then explored HCPs' perceptions as a second stage.

\section{Mapping care pathway}

A qualitative study consisting of a semistructured two-stage email interview was undertaken to answer the research questions. The interview consisted of open-ended questions exploring COPD care pathway in each country. This included five topics: an overview of COPD management and guidelines employed, relationships with other HCPs and teams, support available for patients at home, available community and secondary care, and patients' adherence to medication and lifestyle advice. Five COPD-specialized HCPs representing all clinical partners in the WELCOME project were invited to participate in the study. Once written informed consent to participate was received by email, the first stage interview schedule was sent to the participant. No ethical approval was deemed necessary for the first stage (mapping care pathway) by all clinical partners (refer to Data collection section for list of clinical partners).

\section{HCPs' perceptions}

A qualitative study consisting of face-to-face semistructured interviews was used to elicit HCPs' perceptions on the current COPD patient care pathway in the corresponding country. The interview consisted of open-ended questions exploring HCPs' views on the current care pathway, their day-to-day 
work, barriers and challenges in caring for COPD patients, and the support of other HCPs. The interview was developed in English. The final version was translated from English into two languages: Greek and Dutch.

\section{Data collection}

Data collection was carried out between March and June 2014. The HCPs' face-to-face discussion during the interviews was led by a moderator, and the resulting conversation between the moderator and participants was audio recorded. A convenience and purposive sampling technique was used, with WELCOME project clinical partners identifying HCPs whom they believed to be particularly experienced with COPD care management. Clinical partners in each country approached potential participants to consider taking part in the study. Once permission was obtained, participants were contacted by the researchers, and written informed consent was obtained. This study was approved by the following clinical partners: Beaumont Hospital Ethics (Medical Research) Committee (Dublin, Ireland), Scientific Board of the G. Papanikolaou General Hospital (Thessaloniki, Greece), Medical Research Ethics Committees United (Nieuwegein, the Netherlands), Croydon Health Services NHS Trust Information Governance (London, UK) and University Medical Centre Schleswig-Holstein (Kiel, Germany).

\section{Data analysis}

England and Greek recordings were sent to a third-party transcription service, and Irish and Dutch recordings were transcribed by the research team. The Greek and Dutch transcripts were translated into English by a third-party translation service.

Thematic content analysis was carried out using a structured approach for generating category systems. Burnard et al methodology 28,29 is considered a systematic methodology for recording themes from semistructured interviews that use open-ended questions. Two researchers carried out the data analysis in various stages to reduce the possibility of any researcher bias during the theme development. Themes were confirmed and verified by detailed line-by-line reading of the transcripts, with the process being repeated to identify further themes. The next stage involved making a list of all the themes and eliminating those that had been duplicated. The data were then inspected for any overlapping or similar themes, which were further refined and reduced until a final list of themes was formulated and approved by both researchers.

\section{Results \\ Care pathway mapping}

Figure 1 illustrates the current COPD care pathways in the five countries. The pathway for COPD patients starts with the general practitioner (GP) in England, the Netherlands, and Germany, while in Greece and Ireland, it starts at the hospital (or secondary care).

The values of diagnostic parameters, normal ranges, therapeutic targets, and alerts for COPD patients are slightly different between the five countries. England and Ireland follow the National Institute for Health and Care Excellence COPD guidelines, the Netherlands follows the American Thoracic Society/European Respiratory Society guidelines, Greece follows the Global initiative for chronic obstructive lung disease guidelines, and Germany follows the National Guidelines for the Diagnosis and Therapy of COPD issued by "Deutsche Atemwegsliga" and "Deutsche Gesellschaft für Pneumologie und Beatmungsmedizin".

The follow-up care services differ largely between countries. In England, the follow-up is provided by GP visits, community services, hospital chest clinics, and special clinical teams. The follow-up care services involve GPs, consultants, physiotherapists, and nurses. The special clinical teams, which operate through local respiratory teams, are hospital based but provide services in the community. In addition, England is the only country to provide community services. This includes the respiratory teams and community matrons providing specialist input and basic support including respiratory team clinics, pulmonary rehabilitation (PR), and smoking cessation.

In Ireland, an outreach team consisting of a respiratory consultant, a practice physiotherapist, and nurses provide an early supported discharge, assisted discharge, PR, and transitional care program for inpatients. For outpatients, a service in a respiratory COPD clinic and a PR program are available.

In the Netherlands, the follow-up of patients takes place in primary or secondary care. GPs are involved in the prevention, diagnosis and treatment, and follow-up care of COPD patients, and they have a gate-keeping role. The gate-keeping principle determines what hospital care and specialist care (except emergency care) are needed.

Specialist care involves referral to centers such as CIRO (Centre of Expertise for Chronic Organ Failure) where services such as PR get provided. In Greece, there are no special services provided for outpatients with no role of primary care.

The follow-up parameters are similar and include spirometry-derived pulmonary function measures, body mass 


\section{Germany}

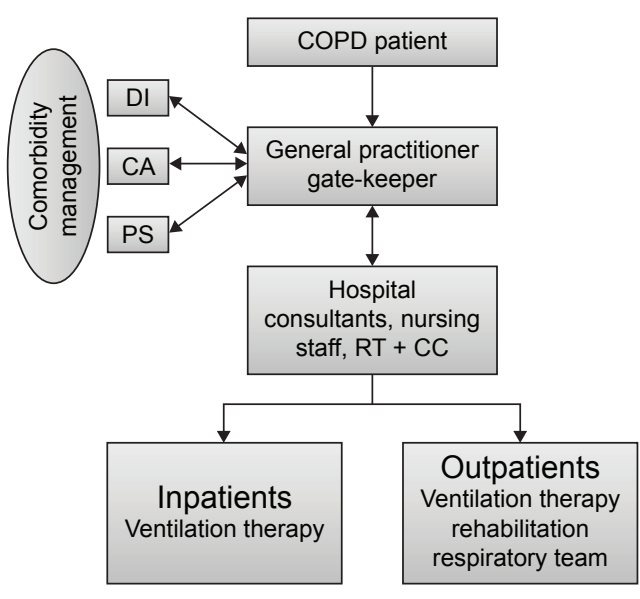

Ireland

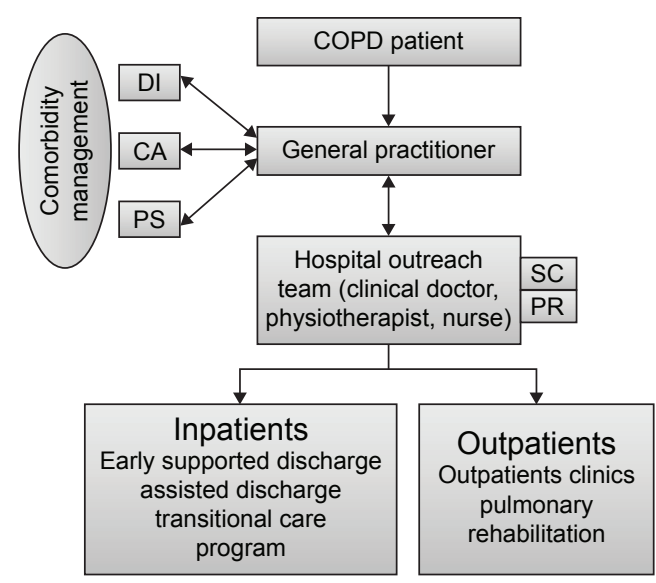

\section{England}

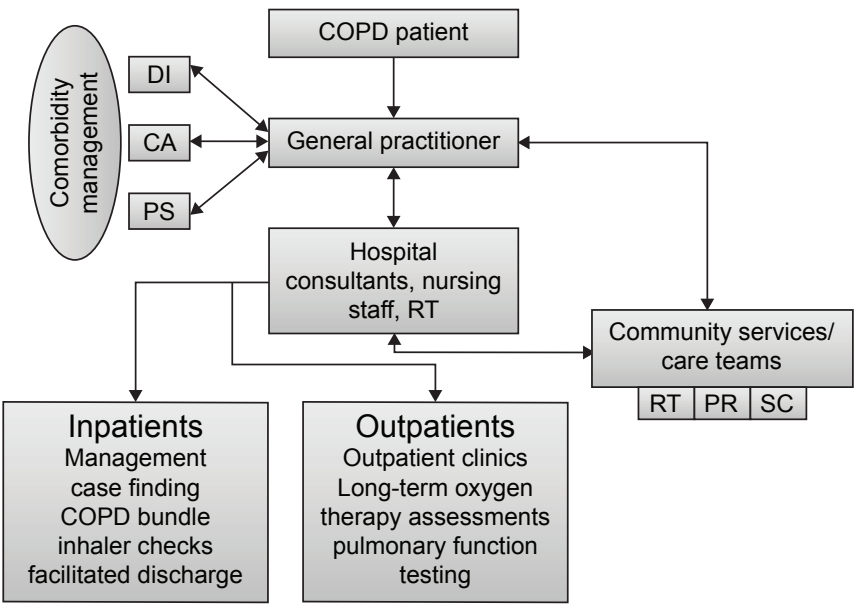

the Netherlands

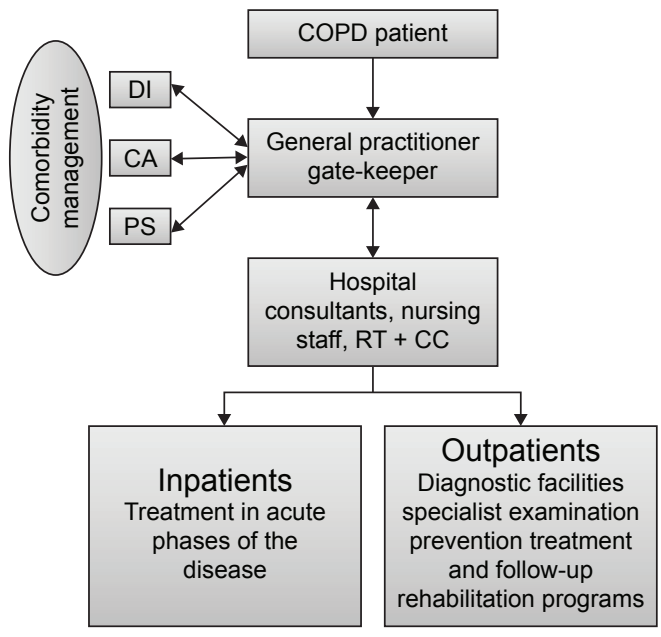

Greece

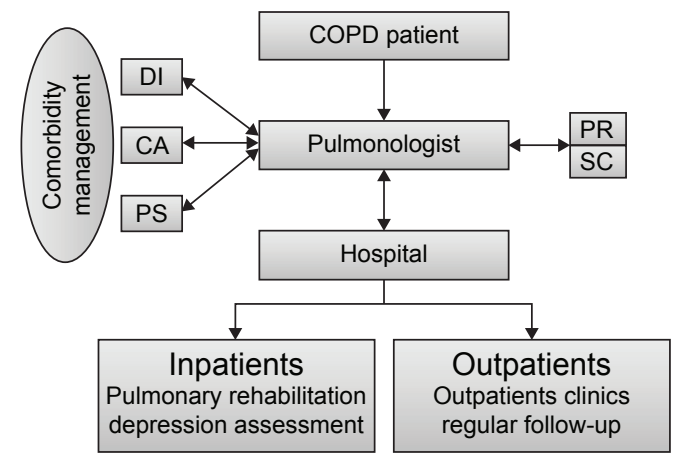

Figure I COPD care pathways in five EU countries.

Abbreviations: DI, diabetologists; CA, cardiologists; PS, psychiatrists; RT, respiratory team; CC, chest clinic; PR, pulmonary rehabilitation; SC, smoking cessation.

index, blood gases, and oxygen saturation. The frequency of the follow-up depends on patients' needs, but in general, it is performed in face-to-face clinics annually in England and biannually in Greece and Ireland.

England and Ireland are the only two countries that currently have special schemes to support patients at home. In
England, a telehealth service is being provided to COPD patients in some districts along with facilitated discharge, management plans for some patients, and rescue packs. In Ireland, several programs are used to support patients at home, but only if the patients meet the inclusion criteria. This includes early supported and assisted discharge, which are interventions 
aiming to accelerate discharge from hospital and providing support in a community setting. ${ }^{30}$ Another service is the transitional care program consisting of actions designed to ensure the coordination and continuity of health care as patients transfer between different locations or different levels of care. ${ }^{31}$

\section{Comorbidities}

The management of COPD with comorbidities (namely, diabetes, heart failure, and mental conditions) was also compared. In the five countries, the same management of COPD is followed even if the patient is diagnosed with comorbidities. Each of the comorbidities is managed independently following its own national guidelines and through separate clinical teams. It is noticeable that the different diagnosed condition services do not communicate with each other directly. In all countries, the GP is mainly responsible for liaising and referring patients between these services and clinical teams, except for Greece where this is done through the pulmonologists.

\section{Adherence and nonpharmacological interventions}

The services being provided for lifestyle management are similar between the five countries. Smoking cessation, advice on annual flu vaccination, advice on importance of PR, and referral to a dietician are example of such services.

The patients' adherence to therapy is monitored differently across the five EU countries. In Greece, the pulmonologists monitor adherence with questionnaires and device demonstration. In England, adherence and nonpharmacological interventions are monitored mainly by the appropriate teams (eg, PR and smoking cessation). In the Netherlands, the patients' adherence is assessed during group sessions (training, education, smoking cessation). No specific services are available in Ireland to monitor adherence to therapy.

Based on our HCPs' interviews, it was noticeable that the role of pharmacists in these countries is seen as limited, and there is no specified role or training for the informal carers (partners, family, and friends).

Table 2 Sample characteristics of interviewed HCPs'

\begin{tabular}{lllll}
\hline Characteristics & England & Greece & the Netherlands & Ireland \\
\hline GPs & $\mathrm{I}$ & & & \\
$\begin{array}{l}\text { Specialist doctors } \\
\text { (cardiologists, }\end{array}$ & 3 & 4 & 3 & 3 \\
$\begin{array}{l}\text { pulmonologists, } \\
\text { diabetologists) }\end{array}$ & & & & \\
Nurses & 3 & & 2 & $\mathrm{I}$ \\
Physiotherapists & $\mathrm{I}$ & & $\mathrm{I}$ & $\mathrm{I}$ \\
Total & 8 & 4 & 6 & 5 \\
\hline
\end{tabular}

Abbreviations: GPs, general practitioners; HCPs', health care professionals.

\section{HCPs' perceptions}

Overall, 23 HCPs were interviewed as shown in Table 2. HCPs reported several issues regarding their view of the current state of care including lack of communication, limited resources, and poor patient engagement.

\section{Lack of communication}

It was evident that there is limited communication between HCPs and that there are challenges in communication between the health care teams in primary and secondary care. Fragmentation of communication between HCPs was highlighted by HCPs; in particular, continuity of care and knowing what happens to patients on a day-to-day basis were described as challenges in their work. In addition, HCPs highlighted the limited involvement of pharmacists in COPD patients care pathways.

Communication with other professionals is a challenge.

Different people involved in the care. So it's very com-

plex in terms of $[\ldots]$ the system is very complex.

\section{Limited resources and information}

Lack of resources in terms of staff, time constraints, and training was voiced as a concern impacting quality of care especially in light of high admission rates with COPD patients. In addition, lack of resources available for patients to contact doctors when they feel sick and knowing how patients' social and economic environment influences their physical condition were also reported as challenges.

A reduction in access to training really and to up-skilling our staff.

They [patients] will go in with a sort of shopping list and I, in theory have 10 minutes to get through it. So it's sort of prioritizing and seeing if I can re-assign appointments when necessary and if it's necessary.

Lack of sort of specialism or specialist's support for the work that we're delivering.

[...] post discharge, we're meant to somehow follow all these patients up with the primary diagnosis of heart failure within two months. It's often not possible.

\section{Poor patient engagement}

HCPs reported poor engagement by patients in their care, and they were not sure how to encourage patients to better manage their medication and treatment of COPD. This is particularly an issue in light of the complications from complex treatment regimens.

Steroid treatments causing hyperglycemia in patients with COPD, patients' lack of compliance with multiple 
medications and patients having multiple co-morbidities which make them difficult to manage.

In addition, information provision and enabling patients to self-manage and recognize problems in good time were reported as challenges.

How well a patient picks up information? Does he remember it? Should I give him a leaflet? Is that enough? Can the patient read? So how do you present the information? How long does he remember it and what will the patient do with the information?

Self-management of comorbidities was also highlighted by HCPs. Diabetologists, for example, described a lack of COPD/diabetic patients' motivation and adherence to prescribed medication:

We have type II who is over 50, 60, 70 and are obese. And no matter what information you give them, there is not the motivation.

[...] a lot of our younger teenagers with type I diabetes, they actually don't cash in the prescriptions for insulin. So in other words they are using about $50 \%$ of the insulin that you prescribed for them for a six-month period.

\section{Pharmacists' involvement}

HCPs thought that pharmacists should play a role in the care of their patients. According to HCPs, pharmacists should facilitate medication monitoring, control medication use, provide patient counseling and education, and play an advising and signaling role by identifying any possible interactions between medicines.

\section{Discussion}

In all five EU countries, our study found that health care pathways are fragmented and care is not integrated properly. COPD and comorbidities are managed separately with no direct communication between different services and care teams. All communication goes through the GPs, or the pulmonologists in Greece, which creates a challenge for HCPs to monitor patients on a day-to-day basis and puts increased pressure on primary care. In addition, services fragmentation has been repeatedly reported as a barrier to the development of more integrated care for patients with complex health care needs. ${ }^{32}$ Integration within and between patient care services and collaboration between HCPs are central to high-quality patient care. ${ }^{33}$ Integrated care consists of different concepts and programs intended to achieve coordination within and between health care delivery systems, with the aim of improving the experience of patients and the outcomes of care and enhancing overall efficiency of the health systems. ${ }^{34}$ In fact, several studies have recently reported the value of integrated care in terms of reducing hospital admission and length of stay while improving patients' adherence to treatment and their satisfaction. ${ }^{35-38}$

There were also country-specific challenges. In England and Ireland, there are several services that tackle certain issues related to COPD management (eg, adherence and smoking), but these are not embedded as part of the care pathway. Thus, the pathways shown in Figure 1 illustrate the typical services but might be missing key services. These missing services only benefit patients on "ad hoc" basis as they have not been embedded in the care pathway or are missing a defined referral procedure.

Despite the fact that pharmacists can play an important role in COPD care delivery, our study found that HCPs are not aware of the benefits of such a role. Literature shows that pharmacist-led interventions can produce cost-savings, provide medicine education, and improve patients' adherence to treatment and health-related QoL leading to a reduction in hospitalization and emergency department visits. ${ }^{39-43}$

Similarly, although the management of COPD is often shared between the patients and their carers including family and/or friends, no defined role was found for them in the care pathway. It is estimated that there were $\sim 125$ million carers in Europe in 2009, and due to the aging population, this number is expected to increase dramatically in the next 10-20 years. ${ }^{44}$ Carers could provide assistance with daily self-management tasks (such as personal care), coordination and interaction with supportive services (such as health appointments), and emotional support. Thus, they can be a strong motivator for patients to continue to live and engage with the complex requirements of self-management. ${ }^{45-50}$ However, lack of professional support is limiting this role, and in fact, this lack has been reported as a factor for the stress informal carers face while providing care to COPD patients. ${ }^{51}$

Self-management is challenging in COPD, and it is influenced by several factors including physical, psychological, social, existential, and providers' issues. ${ }^{52}$ In addition, despite that variety of effective treatment options exist for patients with COPD, long-term adherence to medication is required for treatment success. ${ }^{1}$ Poor patients' engagement and adherence is one of the main factors responsible for failure to achieve treatment goals and may also carry a large economic burden as a result of increased health care costs, as well as increased risk of death and hospital admissions due to exacerbations. ${ }^{53,54}$ Using simplified treatment regimens, increasing patient knowledge about self-management, and 
enhancing provider skills in patient education, communication, and adherence counseling could help in improving patients' adherence and engagement. ${ }^{55}$

Finally, as a result of the large demand that COPD is putting on all health care systems, conventional management is becoming somewhat limited, and more innovative approaches, such as telehealth and telemedicine, are required to achieve better management. ${ }^{56}$ Several systematic reviews have found that innovative approaches, when compared with usual care, show benefits in terms of reduced mortality rates, hospital admissions, and accident and emergency department visits, enhanced QoL, and improved patient self-care. ${ }^{57-61}$ Only England and Ireland currently provide such services for COPD patients to enable them to better manage their condition and its comorbidities.

In order to optimize current care pathways, services and professional integration between care settings is a priority. In addition, better communication between health care providers, establishing a clear role for informal carers, and enhancing patients' engagement are also important factors that help in achieving a better integrated system.

\section{Acknowledgment}

This work was supported by the European Commission under the Information and Communication Technologies (ICT) 7th Framework Programme grant number FP7-611223.

\section{Disclosure}

The authors report no conflicts of interest in this work.

\section{References}

1. Pauwels RA, Buist AS, Calverley PM, Jenkins CR, Hurd SS; GOLD Scientific Committee. Global strategy for the diagnosis, management, and prevention of chronic obstructive pulmonary disease. NHLBI/ WHO Global Initiative for Chronic Obstructive Lung Disease (GOLD) Workshop summary. Am J Respir Crit Care Med. 2001;163(5): 1256-1276.

2. European Lung Foundation. Lung diseases - COPD. Lung disease \& information. 2012. Available from: http://www.europeanlung.org/en/ lung-disease-and-information/lung-diseases/copd. Accessed December 9, 2014.

3. Smith C, Gribbin J, Challen K, Hubbard R. The impact of the 2004 NICE guideline and 2003 General Medical Services contract on COPD in primary care in the UK. QJM. 2008;101(2):145-153.

4. European Respiratory Society. The economic burden of lung disease. In: Gibson J, Loddenkemper R, Sibille Y, Lundbäck B, editors. European Respiratory Society's White Book. Sheffield: European Respiratory Society; 2013.

5. OECD. Health expenditure and financing. OECD statistics-health. 2015. Available from: http://stats.oecd.org/Index.aspx?DataSetCode=SHA. Accessed March 20, 2015.

6. European Respiratory Society. Chronic obstructive pulmonary disease. In: European Respiratory Society's White Book. Gibson J, Loddenkemper R, Sibille Y, Lundbäck B, editors. Sheffield: European Respiratory Society; 2013.
7. Geldmacher H, Biller H, Herbst A, et al. Die Prävalenz der chronisch obstruktiven Lungenerkrankung (COPD) in Deutschland. [The prevalence of chronic obstructive pulmonary disease (COPD) in Germany. Results of the BOLD study]. Dtsch Med Wochenschr. 2008;133(50):2609-2614. German.

8. Irish Thoracic Society. National Respiratory COPD Framework. Dublin: Irish Thoracic Society; 2008.

9. Rutten FH, Moons KG, Cramer M-JM, Grobbee DE, Zuithoff NP, Hoes AW. Recognising heart failure in elderly patients with stable chronic obstructive pulmonary disease in primary care: cross sectional diagnostic study. BMJ. 2005;331(7529):1379.

10. Chatila WM, Thomashow BM, Minai OA, Criner GJ, Make BJ. Comorbidities in chronic obstructive pulmonary disease. Proc Am Thorac Soc. 2008;5(4):549-555.

11. Corsonello A, Incalzi RA, Pistelli R, Pedone C, Bustacchini S, Lattanzio F. Comorbidities of chronic obstructive pulmonary disease. Curr Opin Pulm Med. 2011;17 (Supp1 1):S21-S28.

12. Burgel P-R, Escamilla R, Perez T, et al; INITIATIVES BPCO Scientific Committee. Impact of comorbidities on COPD-specific health-related quality of life. Respir Med. 2013;107(2):233-241.

13. Lou P, Zhu Y, Chen P, et al. Prevalence and correlations with depression, anxiety, and other features in outpatients with chronic obstructive pulmonary disease in China: a cross-sectional case control study. $B M C$ Pulm Med. 2012;12(1):53

14. Nolte E, McKee M, Knai C. Managing chronic conditions: An introduction to the experience in eight countries. In: Nolte E, McKee M, Knai C, editors. Managing chronic conditions Experience in eight countries. Copenhagen: WHO Regional Office Europe; 2008.

15. Nolte E, McKee M. Caring for People with Chronic Conditions: A Health System Perspective. Glasgow: McGraw-Hill International; 2008.

16. Titova E, Steinshamn S, Indredavik B, Henriksen AH. Long term effects of an integrated care intervention on hospital utilization in patients with severe COPD: a single centre controlled study. Respir Res. 2015;16(1):8.

17. See C, Chua G, Choo Y, Wu C, Chee T. Implementation of a COPD Integrated Care Pathway (ICP) programme to improve outcomes of COPD patients. Int J Integr Care. 2013;13(8):1472.

18. Balestracci S, Porcu A, Vignale L, et al. Cost and effectiveness of integrated care intervention on the patients with COPD. Eur Respir J. 2013;42(Suppl 57):P5103.

19. Koff P, Jones RH, Cashman JM, Voelkel NF, Vandivier R. Proactive integrated care improves quality of life in patients with COPD. Eur Respir J. 2009;33(5):1031-1038.

20. Lemmens KM, Nieboer AP, Huijsman R. A systematic review of integrated use of disease-management interventions in asthma and COPD. Respir Med. 2009;103(5):670-691.

21. Casas A, Troosters T, Garcia-Aymerich J, et al. Integrated care prevents hospitalisations for exacerbations in COPD patients. Eur Respir J. 2006;28(1):123-130.

22. Hernández C, Alonso A, Garcia-Aymerich J, et al. Effectiveness of community-based integrated care in frail COPD patients: a randomised controlled trial. NPJ Prim Care Respir Med. 2015;25:15022.

23. Garcia-Aymerich J, Hernandez C, Alonso A, et al. Effects of an integrated care intervention on risk factors of COPD readmission. Respir Med. 2007;101(7):1462-1469.

24. Mak V, D’Ancona G, Rampersad R, Saleem A, Khambh J. Reducing inappropriate high dose ICS prescribing for COPD in primary care using respiratory integrated care virtual clinics. Eur Respir J. 2015; 46(Suppl 59):PA3859.

25. Cecile MA, Maarse JAM, Onno CP, Boudewijn LP, Maureen PMH, Frank WJM. Care delivery pathways for Chronic Obstructive Pulmonary Disease in England and the Netherlands: a comparative study. Int J Integr Care. 2012;12:1-9.

26. Ovretveit J. An introduction to comparative health research. In: Comparative and Cross-Cultural Health Research: A Practical Guide. Ovretveit J, editor. Oxon: Radcliffe Publishing; 1998:1-25. 
27. Nabhani-Gebara S, Kayyali R, Philip N, et al. WELCOME project: what do stakeholders want? In depth analysis of COPD patients, carers and healthcare professional views. Paper presented at: Wireless Mobile Communication and Healthcare (Mobihealth), 2014 EAI 4th International Conference; November 3-5, 2014; Athens, Greece.

28. Burnard P. A method of analysing interview transcripts in qualitative research. Nurse Educ Today. 1991;11(6):461-466.

29. Burnard P, Gill P, Stewart K, Treasure E, Chadwick B. Analysing and presenting qualitative data. Br Dent J. 2008;204(8):429-432.

30. Fearon P, Langhorne P. Services for reducing duration of hospital care for acute stroke patients. Cochrane Database Syst Rev. 2012;(9): CD000443.

31. Coleman EA, Boult C. Improving the quality of transitional care for persons with complex care needs. J Am Geriatr Soc. 2003;51(4): $556-557$.

32. Nolte E, Knai C, Saltman RB. Assessing chronic disease management in European health systems Copenhagen: WHO Regional Office Europe; 2014.

33. Leape L, Berwick D, Clancy C, et al. Transforming healthcare: a safety imperative. Qual Saf Health Care. 2009;18(6):424-428.

34. European Lung Foundation. Lung diseases - COPD. Lung disease \& information. 2012. Available from: http://www.europeanlung.org/ en/lung-disease-and-information/lung-diseases/copd. Accessed December 9, 2014.

35. Martínez-González NA, Berchtold P, Ullman K, Busato A, Egger M. Integrated care programmes for adults with chronic conditions: a metareview. Int J Qual Health Care. 2014;26(5):561-570.

36. Lemmens KM, Lemmens LC, Boom JH, et al. Chronic care management for patients with COPD: a critical review of available evidence. J Eval Clin Pract. 2013;19(5):734-752.

37. Adams SG, Smith PK, Allan PF, Anzueto A, Pugh JA, Cornell JE. Systematic review of the chronic care model in chronic obstructive pulmonary disease prevention and management. Arch Intern Med. 2007;167(6): 551-561.

38. Niesink A, Trappenburg J, De Weert-van Oene G, Lammers J, Verheij T, Schrijvers A. Systematic review of the effects of chronic disease management on quality-of-life in people with chronic obstructive pulmonary disease. Respir Med. 2007;101(11):2233-2239.

39. Khdour MR, Kidney JC, Smyth BM, McElnay JC. Clinical pharmacyled disease and medicine management programme for patients with COPD. Br J Clin Pharmacol. 2009;68(4):588-598.

40. Mehuys E, Boussery K, Adriaens E, et al. COPD management in primary care: an observational, community pharmacy-based study. Ann Pharmacother. 2010;44(2):257-266.

41. Jarab AS, AlQudah SG, Khdour M, Shamssain M, Mukattash TL. Impact of pharmaceutical care on health outcomes in patients with COPD. Int J Clin Pharm. 2012;34(1):53-62.

42. Ottenbros S, Teichert M, de Groot R, et al. Pharmacist-led intervention study to improve drug therapy in asthma and COPD patients. Int J Clin Pharm. 2014;36(2):336-344.

43. Wright $\mathrm{D}$, Twigg $\mathrm{M}$, Thornley $\mathrm{T}$. Chronic obstructive pulmonary disease case finding by community pharmacists: a potential cost-effective public health intervention. Int J Pharm Pract. 2015;23(1):83-85.
44. Glendinning C, Tjadens F, Arksey H, Moree M, Moran N, Nies H. Care provision within families and its socio-economic impact on care providers: report for the European Commission DG EMPL negotiated procedure VT/2007/114. York: University of York; 2009.

45. Cicutto L, Brooks D, Henderson K. Self-care issues from the perspective of individuals with chronic obstructive pulmonary disease. Patient Educ Couns. 2004;55(2):168-176.

46. Ek K, Ternestedt BM. Living with chronic obstructive pulmonary disease at the end of life: a phenomenological study. J Adv Nurs. 2008; 62(4):470-478.

47. Halding A-G, Wahl A, Heggdal K. 'Belonging'. Patients' experiences of social relationships during pulmonary rehabilitation. Disabil Rehabil. 2010;32(15):1272-1280.

48. Kanervisto M, Kaistila T, Paavilainen E. Severe chronic obstructive pulmonary disease in a family's everyday life in Finland: perceptions of people with chronic obstructive pulmonary disease and their spouses. Nurs Health Sci. 2007;9(1):40-47.

49. Bourbeau J. Clinical decision processes and patient engagement in selfmanagement. Dis Manage Health Outcomes. 2008;16(5):327-333.

50. Jassem E, Kozielski J, Górecka D, Krakowiak P, Krajnik M, Slominski JM. Integrated care for patients with advanced chronic obstructive pulmonary disease: a new approach to organization. Pol Arch Med Wewn. 2010;120(10):423-428.

51. Grant M, Cavanagh A, Yorke J. The impact of caring for those with chronic obstructive pulmonary disease (COPD) on carers' psychological well-being: a narrative review. Int J Nurs Stud. 2012;49(11): 1459-1471.

52. Disler R, Gallagher R, Davidson P. Factors influencing self-management in chronic obstructive pulmonary disease: an integrative review. Int $J$ Nurs Stud. 2012;49(2):230-242.

53. Mäkelä MJ, Backer V, Hedegaard M, Larsson K. Adherence to inhaled therapies, health outcomes and costs in patients with asthma and COPD. Respir Med. 2013;107(10):1481-1490.

54. Vestbo J, Anderson JA, Calverley PM, et al. Adherence to inhaled therapy, mortality and hospital admission in COPD. Thorax. 2009;64(11): 939-943.

55. Lareau SC, Yawn BP. Improving adherence with inhaler therapy in COPD. Int J Chron Obstruct Pulmon Dis. 2010;5:401-406.

56. Smitha SM, Elkina SL, Partridgeb MR. Technology and its role in respiratory care. Prim Care Respir J. 2009;18(3):159-164.

57. Inglis S. Structured telephone support or telemonitoring programmes for patients with chronic heart failure. J Evid Based Med. 2010;3(4):228.

58. Polisena J, Tran K, Cimon K, et al. Home telehealth for chronic obstructive pulmonary disease: a systematic review and meta-analysis. J Telemed Telecare. 2010;16(3):120-127.

59. McLean S, Nurmatov U, Liu J, Pagliari C, Car J, Sheikh A. Telehealthcare for chronic obstructive pulmonary disease. Cochrane Database Syst Rev. 2011;(7):CD007718.

60. Purcell R, McInnes S, Halcomb EJ. Telemonitoring can assist in managing cardiovascular disease in primary care: a systematic review of systematic reviews. BMC Fam Pract. 2014;15(1):43.

61. Cruz J, Brooks D, Marques A. Home telemonitoring effectiveness in COPD: a systematic review. Int J Clin Pract. 2014;68(3):369-378.
International Journal of COPD

\section{Publish your work in this journal}

The International Journal of COPD is an international, peer-reviewed journal of therapeutics and pharmacology focusing on concise rapid reporting of clinical studies and reviews in COPD. Special focus is given to the pathophysiological processes underlying the disease, intervention programs, patient focused education, and self management protocols.
Dovepress

This journal is indexed on PubMed Central, MedLine and CAS. The manuscript management system is completely online and includes a very quick and fair peer-review system, which is all easy to use. Visit http://www.dovepress.com/testimonials.php to read real quotes from published authors. 